\title{
XHOSA AS MEDIUM OF INSTRUCTION IN HIGHER EDUCATION: PIE IN THE SKY?
}

\author{
Bertie Neethling \\ University of the Western Cape
}

This article debates the possibility of introducing Xhosa as a Medium of Instruction (MoI) at tertiary level. It should be seen as an argumentative contribution that comprises the following methodological steps: (a) a look at the language stipulations in the Constitution, (b) a brief survey of the advocacy of Neville Alexander (2003, 2006) regarding the development of the indigenous languages to serve as MoI, (c) an analysis of the directives from educational authorities pertaining to this matter, and $(d)$, a brief comparative view of the language policies of three universities in the Western Cape, i.e. Cape Town, Stellenbosch and the Western Cape, undertaken to assess how these institutions have responded to the directives from educational authorities to develop Xhosa as a language of teaching and learning at tertiary level.

It is argued that, despite exciting and innovative developments around developing multilingualism on all three campuses, the matter around developing Xhosa as a medium of instruction in higher education is receiving very little attention and could at best be seen as a possible long-term goal. It is further argued that the introduction of Xhosa as a medium of instruction in the schooling system should precede attempts to introduce it as a medium of instruction in higher education.

Keywords

Xhosa, Medium of Instruction, Higher Education

\section{INTRODUCTION: LANGUAGE STIPULATIONS IN THE SOUTH AFRICAN CONSTITUTION}

Although South Africa is a multilingual and multicultural country, this particular facet of South African society was seldom foregrounded or highlighted before 1994. It was, of course, always there in the 'subtext', but very often simply sidelined or ignored. All of this has changed quite dramatically since 1994. In what clearly was a political move and quite understandable at that point, the elevation of all the main indigenous Bantu ${ }^{1}$ languages, nine of them, to being 'official' alongside English and Afrikaans, was announced. South Africa all of a sudden had 11 official languages. This was backed up by the Constitution of the 'new' South Africa, one widely hailed as an exemplary one that was finally adopted in 1996 (Act 108 of 1996). In the Constitution, in the 'Founding Provisions' section, it is stipulated that 'all official languages must enjoy parity of esteem and must be treated equitably' (p.4). Then, in Chapter 2, the Bill of Rights, the following is found under the 'Education' rubric: 
Everyone has the right to receive education in the official language or languages of their choice in public educational institutions where that education is reasonably practical. In order to ensure the effective access to, and implementation of, this right the state must consider all reasonable educational alternatives, including single-medium institutions, taking into account-
(a) equity
(b) practicability; and
(c) the need to redress the results of past racially discriminatory laws and practices.

One does not have to be a language expert to clearly see the tension between 'rights' and what one could call 'escape clauses' such as 'reasonably practical', 'reasonable....alternatives' and 'practicability'. The stipulations do, however, imply that public educational institutions should apply their minds to the development of the indigenous languages as mediums of instruction. This obviously also includes the school system, and the debate in South Africa about the widely supported notion of mother tongue education also at that level is ongoing. Although one might (and probably should) argue that mother tongue education at school level should be introduced gradually and preferably up to matric level before one could consider the situation in higher education, it is not the purpose of this contribution to debate the language issue at school level.

Besides outlining the advocacy by Alexander, the main purpose with this contribution is to identify policy directives from the South African government regarding the development of the indigenous languages, and then to assess the development and possible progress within this context in South Africa up to the present day, with particular reference to the language policies of the three 'traditional' universities in the Western Cape in South Africa, i.e. the Universities of Cape Town (UCT), the Western Cape (UWC), and Stellenbosch (US) (former technicons, now called Universities of Technology, are excluded). There are significant numbers of Xhosa-speaking students at UCT and UWC, although the number at Stellenbosch is very small. Xhosa is, however, the most dominant indigenous language in the Western Cape by far.

Despite their so-called autonomy and independence, all three institutions certainly are, to some extent, dependent on state subsidy and hence could be considered as 'public educational institutions'. The obvious question then is: how have these institutions responded to the challenge posed in the Constitution, as well as in other policy documents, i.e. to actively promote the development and introduction of Xhosa as a medium of instruction?

\section{SUSTAINABLE DEVELOPMENT: THE ADVOCACY BY NEVILLE ALEXANDER}

Neville Alexander, heading PRAESA (Project for the Study of an Alternative Education in South Africa) in Cape Town, has been campaigning relentlessly for the promotion and development of not only the indigenous South African languages (or languages from the Bantu family), but all other African languages, to perform the highest possible functions, inter alia also serving as mediums of instruction at universities. Although his viewpoints are known by many and also supported by other scholars, it would be useful to briefly look at some of his selected writings $(2003,2006)$ in order to contextualise the particular problem around the medium of instruction debate. He asks the following question to describe the reluctance to 
seriously pursue this matter: 'Why bother to 'develop' African languages as media of instruction at tertiary educational institutions, given that we have English (and decreasingly, Afrikaans) as perfectly useable formal academic language(s)?' (2006:1). He then argues why this is necessary, and some of his viewpoints are discussed below.

It seems as if the colonial languages have not only taken preference over the indigenous languages across all of Africa, but are, in fact, threatening their existence: '....colonial conquest, imperialism and globalisation have established a hierarchy of standard languages, which mirrors the power relations on the planet. The overall effect of this configuration has been to hasten the extinction of innumerable language varieties and to stigmatise and marginalise all but the most powerful languages' (2003:5). The hegemonic status that English and French have acquired '...clearly reflects the dependency relationship that shackles the African elites to their former colonial and imperial overlords' (2006:5).

In the 2006 publication, Alexander propagates a so-called 3Ds frame of reference for the promotion and upliftment of the indigenous languages, i.e. development, diversity, and democracy. Alexander makes it quite clear that '....the dialectic of capitalist development will not bypass the continent of Africa' (2006:1). In moving the focus to language, it would appear that all across the world where higher education was conducted in the language of the dominant or imperial power there are examples to show how those languages were displaced by the local varieties once these local languages were developed to the point where they could do so. Only in the colonies of Great Britain and France has this process been an exceptionally slow one, particularly also in Africa.

Regarding the diversity argument, the proposition is also put forward by Alexander that '...cultural and, therefore linguistic diversity is as necessary as biodiversity for the survival and perpetuation of the human species' (2003:7). One can liken the death of any language to the disappearance of a species. Alexander also stresses the importance of language as a vital element for most people regarding individual and social identity. Language is often seen as '...the defining element' of identity (2006:3).

The democracy principle comes to the fore to "point both in the direction of language as a human right and, more pertinently, to language as a socio-political and socio-economic resource' (2006:4). Alexander refers to the hegemonic status of English and French in Africa, stating clearly that maintaining this practice simply does not reflect the interests of the masses of the African people. The democracy principle is driven home forcefully:

Lest there be any misunderstanding, let me state clearly that the democracy argument is based on the assumption that the political and cultural leadership of the continent are genuinely committed to the eradication of poverty, disease, ignorance and all forms of discrimination. (2006:4)

Although one might think that Alexander's views are too idealistic and his judgement at times too harsh, the combined arguments put forward by him regarding the preservation and development of the indigenous languages of Africa are worthy of serious consideration. Working in South Africa, it comes as no surprise that Alexander has been involved in various initiatives from the South African government to formulate directives and, eventually, policy on language development matters. His struggle credentials might have endeared him to the present government, but one would like to believe that he is recognised as a language expert. It is actually ironic that many of his explicit views on language development and 
implementation are not strongly supported in government circles in terms of public support or policy.

\section{DIRECTIVES FROM THE SOUTH AFRICAN EDUCATIONAL AUTHORITIES}

In turning to the earlier question regarding the response of the three Western Cape universities to the challenge posed in the Constitution of South Africa of developing the indigenous languages, one can, as a starting point, look at guiding documents from government around this matter. Initially, the Ministry sought advice from the Council on Higher Education who drew up a report called Language Policy Framework for South African Higher Education (2001). In the section on background it is pointed out that only English and Afrikaans were at that point functioning as mediums of instruction in institutions of higher education. Early in the document the then Minister of Education acknowledges that 'in the light of practical and other considerations it will be necessary to work within the confines of the status quo until such time as other South African languages have been developed to a level where they may be used in all higher education functions' (p.10). In the summary of the document, the policy framework supports 'the development, in the medium to long term, of South African languages as mediums of instruction in higher education, alongside English and Afrikaans' (p.15). The development of multilingualism is also encouraged in 'institutional policies and practices' (p.16).

This report informed the 2002 document entitled Language Policy for Higher Education from the Ministry of Education. The document quotes from the Constitution (p.4), that 'the state must take practical and positive measures to elevate the status and advance the use of these [= indigenous] languages'. The Ministry outlines its challenge as 'to ensure the simultaneous development of a multilingual environment in which all our languages are developed as academic/scientific languages, while at the same time ensuring that the existing languages of instruction do not serve as a barrier to access and success' (p.5). Subject to this policy determined by the Minister, the Councils of public higher education institutions with their respective senates must then determine the language policy of such a higher education institution and must publish and make available such policy on request. According to Alexander (2006:12), the purpose was to see at a glance whether they were in compliance with the legislation.

The universities in question all seem to have adhered to the call to develop language policies on their respective campuses. Documents outlining these policies are freely available, either on the websites of the institutions, or on request. From an ethical point of view, it is accepted that these are public documents open for discussion and interpretation.

The three institutions have widely differentiating histories, though, and differ from one another in many respects up to this day. Although all three institutions attract students from all over the world, and have exchange agreements with a host of other universities, they share one very important feature pertaining to language: being so close together they essentially serve the same language communities. All provinces in South Africa have their own official regional languages. In the Western Cape it is Afrikaans (the majority language), English and Xhosa. All three universities reflect a diverse campus in terms of the represented first languages of students, but the student population at all three come overwhelmingly (as high as 80\%) from English-, Afrikaans- and Xhosa-speaking communities. Within the context of this contribution, the spotlight then is on Xhosa and its possible development to enable it to function as a medium of instruction in higher education. 
In March 2005, the Ministerial Committee released its report to the Minister of Education. It was called The Development of Indigenous African Languages as Mediums of Instruction in Higher Education. In the 'Executive Summary' (p.4) the committee remarks that 'The Language Policy for Higher Education was well received by higher education institutions'. This, in a way, suggests that institutions may have taken up the challenge to put strategies in place and to devote time, energy and resources towards developing the indigenous languages so that they may eventually serve as mediums of instruction. The reader is then somewhat surprised when the committee, just one page further, comments very gloomily about the prospects around such a development: 'Emanating from our deliberations is our strong view that a crisis is looming in South Africa regarding the preservation, maintenance and associated identity of our indigenous African languages'(p.5); and further: 'The future of the indigenous African languages as mediums of instruction is bleak unless a long-range plan is devised that could be implemented as a concerted effort over the next two to three decades.' (ibid). This is again stressed on the next page: 'The committee members would like to reiterate that, unless urgent measures are taken, South Africa's indigenous languages are under serious threat' (p.6).

It is very likely that the committee members may have been very negatively influenced by the situation at the time, which is still persisting today. At institutions of higher learning in South Africa, particularly universities, the numbers of students enrolling for first-language study courses in the Bantu languages, have, over the last decade, been dwindling to such an extent that such departments were under threat to be closed down in some areas. This clear indication of a lack of interest by students in furthering the knowledge of their own languages was alarming. Graduates majoring in the Bantu languages are sorely needed, because they are likely to play an important role in any future development of these languages. Departments in general are still struggling with student numbers. A case in point is the Xhosa Department at the University of the Western Cape. Throughout the 90s this department was the fastest growing one on the UWC campus and at one point had 1900 undergraduate students. Over the last decade the first-year intake was between 30 to 40 students, with the resultant lower figures beyond the first year. This crisis is also alluded to by Alexander (2003:26).

\section{LANGUAGE POLICY AT THE THREE WESTERN CAPE UNIVERSITIES}

The respective language policies of the three universities in question seem to suggest that not one of the universities has a clear plan to develop the dominant indigenous language in the Western Cape, i.e. Xhosa. It is not the purpose here to analyse the language policies in any great detail, but to reflect on the position afforded to Xhosa in the available documents. It might, of course, be that students and staff at these institutions hold different opinions around this matter, but their opinions have not been sought. Any initiative of this nature should be institutionally driven.

Given their respective different historical backgrounds, it does not come as a surprise to learn that Cape Town (UCT) has always functioned as an English-speaking university in all respects. It has never bothered to accommodate Afrikaans- or Xhosa-speaking students in terms of medium of instruction or as languages of learning. Its current website has snippets of Afrikaans and Xhosa, but that can best be described as 'window dressing'.

The UCT Language Policy document that is available on the website was adopted by Senate and Council in 1999 and revised in 2003. English is foregrounded as the 'medium of 
instruction and administration', and students are expected to 'acquire effective literacy' in English. The starting point of the policy is 'the need to prepare students to participate fully in a multi-lingual society, where multi-lingual proficiency and awareness are essential'. To develop the 'proficiency' and the 'awareness', other language and literature departments 'are expected to play a key role in exploring ways' of assisting UCT in this regard. It is fairly clear that there were no clear plans around implementation when the policy was drafted. Xhosa is not mentioned by name at all. In 2003 a task team was appointed to, amongst others, focus on the issue of 'languages of instruction' and to report to senate. The report focused more on raising awareness of multilingualism, and to encourage other faculties to also introduce service courses in Xhosa. It does say (p.2) that it 'makes most sense' to allocate resources to improving proficiency in the three languages of the region, and that 'we are mindful of the opportunities presented for joint development of Xhosa with the other tertiary institutions in the Western and Eastern Cape'. The possibility of developing Xhosa to the level where it could function as a medium of instruction is not mentioned.

Stellenbosch (US), by contrast, has been an Afrikaans-speaking institution that has always attracted and accommodated-English speaking students, even at the level of medium of instruction. Xhosa did not feature aside from being a subject of study. Its current website, though, is available both in Afrikaans and English, and even Xhosa is emerging in certain sections. Given the low profile that Xhosa has in the current language debate at Stellenbosch, this could ostensibly also be seen as 'window dressing' at this point.

At Stellenbosch the language debate on campus in recent years attracted the most attention by far. The main issue did not involve Xhosa, however, but focused on English being introduced at undergraduate level in the Arts Faculty alongside Afrikaans after the university had accepted the so-called T-option $(\mathrm{T}=$ 'Tweetaligheid' = Bilingualism). For many Afrikaans supporters this signalled the first signs of a wavering Afrikaans position that, in the long run, would succumb to the relentless pressure of the 'bigger' and more 'powerful' English language. Central in the debate stood the then Rector, Chris Brink, who since his arrival on the US campus in 2002, was instrumental in transformation processes. The battle lines were quickly drawn and the rector with his uncompromising stand on many aspects soon alienated himself from a significant, although generally older, segment of the university. He added fuel to the fire when, in 2006, he published a book, in English, on the matter called No lesser place - the taaldebat (= language debate) at Stellenbosch. He argued that the debate about Afrikaans had been conducted almost entirely within Afrikaans and hence was not heard by all, hence his decision to write in English (2006:1). Soon afterwards he left the employ of the university.

It seems that the structures assigned to formulate policy and implementation are quite active at the US and the process is reasonably transparent. Notwithstanding the apprehension one might feel regarding the eventual outcome of events, with particular reference to the future of Afrikaans, there seems to be a sincere effort to safeguard Afrikaans, on the one hand, and at the same time open up opportunities for English and, eventually, possibly also for Xhosa. Xhosa is described as 'an emerging academic language', but there is no indication as to how the US would develop it further. The language debate at Stellenbosch is ongoing. It is probably understandable that Stellenbosch, because of the constant pressure not to use Afrikaans as a barrier to access, as well as the pressure to retain its Afrikaans character and ethos, has not been more active in taking steps to promote Xhosa as a language of teaching and learning. Initiatives in the Education Faculty at Stellenbosch will be discussed later on. 
The University of the Western Cape (UWC) is the only one of the three universities at which the medium of instruction has actually changed, namely from Afrikaans to English. This came about when UWC started to challenge the principles on which it was founded in the apartheid years and positioned itself as the 'intellectual home of the left'. This, as part of transformation, meant breaking with Afrikaans as a medium of instruction. At the time, Afrikaans was closely associated with the apartheid government and UWC ostensibly felt that it could not oppose apartheid (and in so doing align itself with groupings that were in the main using English as a lingua franca) and continue to retain Afrikaans as the sole medium of instruction. Although Afrikaans and English were used alongside one another in the classroom for some time in a parallel fashion depending on the composition of the class, Afrikaans gradually gave way to English, particularly because Xhosa-speaking students in the late 80s starting enrolling at UWC in significant numbers, and they, in general, were more comfortable with English than with Afrikaans as the language of learning and teaching. Up till today Xhosa has not been accommodated. UWC's current website is only available in English, with Afrikaans and Xhosa not featuring at all.

At the Western Cape (UWC) the language policy recognises the multilingual nature of UWC, but then declares English as the language of teaching. Staff members competent in Afrikaans or Xhosa are encouraged to use these to facilitate communication or discussion. Regarding assessment, it is recommended that all three languages be used in setting tasks/assignments/examinations 'wherever it is practicable to do so', but English is to be used for answering, being 'the most prominent academic language internationally' and the 'most readily accessible to South Africans' (p.1). In practice, very little happens regarding the noble intentions of assisting Afrikaans and Xhosa speakers, although Peck $(2008: 57,59)$ indicates that Xhosa-speaking students in tutorial sessions do use Xhosa to discuss the work before they formulate a response to the (usually) non-Xhosa speaking tutor. Xhosa then seems to be used sporadically as a language of learning in such tutorial contexts.

It is reasonably clear that all three universities recognise the diversity of their student populations, also in terms of language, but there is no clear plan to consciously and actively promote Xhosa at any of the three institutions.

\section{LANGUAGE POLICY AND IMPLEMENTATION IN HEIs: THE OCTOBER 2006 CONFERENCE}

In October 2006 a conference called Language Policy and Implementation in HEIs (Higher Education Institutions) was organised by the South African government on the University of South Africa campus in Pretoria. It apparently was an initiative to revive the issue around language policy at higher education institutions, including, inter alia, the question around the medium of instruction. Despite the unambiguous focus suggested by the conference title, few speakers actually focused on the medium issue. Only Mbulungeni Madiba (UCT), in his contribution titled Mediums of Instruction at Higher Education Institutions in South Africa, addressed the question directly by outlining the existing practices. He identified three typologies:

Typology 1 (SEMI): Supported English Medium of Instruction (the support coming in the form of multilingual glossaries); 
Typology 2: Combinational approach, involving two languages, usually English and Afrikaans (Stellenbosch and Potchefstroom);

Typology 3: Historically Black Universities (HBUs) with no clear policy but mainly using English.

He emphasised the point that, whereas most universities had developed language policies that suggested how multilingualism would be promoted in general communication and outlook, the implementation of multilingualism in teaching and learning seemed to pose a serious challenge. This view was supported by the language policies of the three Western Cape universities briefly outlined above. He also made the point - also evident from the government reports - that there seemed to be an emphasis on development before languages could be introduced as mediums of instruction.

Naledi Pandor, the Minister of Education at the time, and also a speaker at the conference, was brave enough to acknowledge that the political leadership in promoting multilingualism was lacking, and that issues around language was not yet 'a popular concern' in South Africa. Alexander (2003:32) was quite outspoken about this matter: 'Let me also stress ... what ought to be a superfluous proposition but unfortunately is not. Nothing will happen unless the government and the private sector make the knowing of African languages worthwhile'. In many circles the lacklustre response of the South African government towards language matters is lamented. Whether the political will exists to oversee and actually facilitate implementation is questioned (see also Webb, 2002, in this regard). Viljoen (2006), dealing with a contribution around the role of the state and languages of tuition at universities, stresses the role of the state to introduce practical and implementable measures to elevate the status and use of the indigenous languages. In his opinion, the state has a constitutional and financial obligation in promoting the indigenous languages as mediums of instruction at tertiary level, and cannot expect the institutions themselves to foot the bill in this regard (2006:3,5).

Minister Pandor did, however, announce that it was envisaged to extend mother tongue instruction in the schools to the first six years, supported by exposure to a second language. This is a step in the right direction. The question around the medium of instruction should not be dealt with from the top down, but from the bottom up. It is highly unlikely that the indigenous Bantu languages will be developed and implemented as mediums of instruction if learners at school are not educated in the language of their choice, as the Constitution stipulates. There are indications that, in some township schools as well as in certain rural areas in the Eastern and Western Cape, learners are indeed taught in the language of their choice, i.e. Xhosa, although the learning material is primarily in English only and they are still required to write their final school-leaving examination in English. Although not ideal, this situation is probably better than having teachers who are ill-equipped to teach through the medium of English.

Even if the medium of instruction beyond school is to remain English, for example, research all across the world seems to have proved that learners, once their cognitive skills are firmly rooted in their first language, find it relatively easy to acquire or switch to another language (like English) to which they have been exposed. This line of thought, i.e. a mother-tonguebased bilingual education at school, is widely supported, inter alia also by Alexander (2003:27) who outlines the ideal system as follows: '...what we have to propagate immediately, intensively and continuously, is the rehabilitation of mother-tongue education 
within the context of a bilingual educational system where the other language in most cases will be English.' He therefore argues strongly for the retention of English, but as a second and supportive language to the mother tongue.

\section{THE DOMINANCE OF ENGLISH}

One should not forget that many inhabitants of South Africa are exposed to English daily through the mass media, particularly television with intensive audio input, hence an underlying base, even if passive and not productive, is established. With a sound firstlanguage education at school, this passive internalisation could be reasonably easily transformed into a productive mode. The current situation in the South African schools is not conducive to the implementation of the indigenous languages as mediums of instruction at institutions of higher learning. Unless the schools adopt an approach that supports mother tongue tuition, it is probably unlikely that the mediums of instruction at institutions of higher education will change.

It is unfortunately so that a number of factors militate against the acceptance of mother tongue instruction in the South African context, and some of these factors are worthy of consideration. A fairly serious problem in South Africa is that many parents, also Xhosaspeaking ones, believe that the 'language of choice' need not be the mother tongue, but should rather be English (see also Benson, 2005). English, they believe, will open doors in terms of employment opportunities. This perception is extremely strong, and unless parents can be convinced that an education at school in the mother tongue will not stand in the way of such opportunities, it will be difficult to turn this perception around. Alexander (2003:28) phrases this well: 'We have to persuade our communities about the potential of African languages as languages of power and languages of high status.'

The worldwide globalisation issue is another strong factor favouring English. English undoubtedly equips one to interact in a host of contexts beyond the South African border. One simply cannot do that with Xhosa, Sotho or Venda, or any of the other indigenous languages. Even Afrikaans is much better situated than the other local indigenous languages in this regard. Dutch, spoken in the Netherlands and Belgium, is relatively easily understood by Afrikaans speakers and so is Afrikaans by the Dutch speakers. Should the Bantu languages become mediums of instruction at universities, for example, research findings might be published in the particular languages, which could be interpreted as a necessary and welcome development. The downside to such a scenario is that one may isolate oneself from international scholarship, which will never be exposed to one's work unless one also pursues publication in a more widespread language like English. It is crucially important to remain part of international scholarship, therefore language should not become an obstacle in this regard. Alexander (2003:11) also makes it clear that the resistance against English is not a question of 'anglophobia', despite the lamentable view of many that English is 'God's gift to humanity' (ibid.). He stresses the fact that English as a global language is here to stay, and that the opposition is rather aimed at the hegemonic position of English that puts other languages at risk to the point of threatening them with extinction (Alexander, 2003:12).

\section{XHOSA AS EMERGING LANGUAGE ON UNIVERSITY CAMPUSES}

Xhosa is receiving attention at all three Western Cape universities, but the aim of developing the language as a medium of instruction seems to be lacking. The Education Faculty at Stellenbosch expects their prospective teachers to qualify in two languages (a choice between 
English, Afrikaans and Xhosa). Although Xhosa-speaking candidates are few, the opportunity to become qualified teachers teaching school subjects through the medium of Xhosa therefore does exist and this represents an effort to strengthen the use of Xhosa as a medium of instruction at school level (Prof. C. van der Walt [US] pers. comm.). On all three campuses there are, however, exciting developments in the area of 'service courses' that are available and are often compulsory for students in other faculties. BEd students at Stellenbosch have to do the third language (the one not chosen as the teaching language) as a communication module. Future medical doctors at both Stellenbosch and UCT are compelled to do an introductory Xhosa course aimed at equipping them with communicative skills in the health sector (Prof. M. Visser [US] and Dr A. Nyamende [UCT] pers. comm.). At UWC (where there is no medical faculty) such courses are offered in the Community and Health Sciences faculty (different target groups), as well as to Pharmacy and Dentistry students. This is a welcome development that appropriately foregrounds Xhosa as an indispensable communication medium, particularly in the health sector context. It is foreseen that this development may well be extended to other faculties in future.

At UCT an interesting glossary project has been launched in the Economics department (see Paxton, 2009). The aim, inter alia, was also to give Xhosa-speaking students the opportunity to discuss and develop new economic concepts in their own language, in order to facilitate a better understanding of such concepts. Paxton argues that the project's findings suggest that students, through code switching, use different discourses and languages to negotiate the meaning of unfamiliar terms. This seems to be an example of Madiba's SEMI (Supported English Medium of Instruction) Typology referred to earlier. It certainly has merit, and such initiatives should be welcomed as an interim measure towards developing the indigenous languages as mediums of instruction, also in higher education.

Another context in which the three universities also seem to have agreed to accommodate Xhosa (already or in future) is through multilingual signage on their respective campuses. Xhosa-speaking students are likely to feel more 'at home' should this be realised, but it should be clear that neither of these two initiatives (the service courses and the signage issue), welcome as they are, contribute much to the development of Xhosa as a medium of instruction at institutions of higher education.

Neville Alexander was the convenor of the working group of the Department of Education on language policy that drafted the original recommendations released in 2002 . He stresses the following recommendation (Alexander, 2003:29): 'First of all, all higher education institutions should participate in facilitating and promoting the goal of the National Language Policy to develop all South African languages in such a manner that they can be used in all high status functions, especially as formal academic languages at higher education level'. This was further qualified in the 2005 document from the Department of Education: 'Each higher education institution should be required to identify an indigenous African language of its choice for initial development as a medium of instruction. Where the language of choice is a particular regionally dominant language, higher education institutions in that particular region should develop a regional approach' (Recommendation 48.8, p.24). Alexander (2003:30) had already explicated this earlier: 'The basic idea is that a university or a group of universities would be given the task of developing specific languages such as isiZulu, or isiXhosa, or Sesotho, or Setswana and over a period of 10 to 15 years, steps would be taken to ensure that each of the languages concerned is developed in that particular manner. A step-by-step development and implementation plan should be formulated for each of the relevant languages, such that, among other things, it will be clear when they will be able to be used as 
languages of tuition in specific disciplines'. In the Western Cape this is easy, seeing that Xhosa is the dominant indigenous language by far in the region, particularly in the Cape Metropole and Stellenbosch.

Whether all higher education institutions, including the three Western Cape universities, are acquainted with the above recommendations is not clear, and it is equally unclear whether any exploratory discussions around this matter have taken place or have been arranged for the near future in the Western Cape. One can only deduce that the three institutions do not know about the recommendation (which is probably unlikely), or do not regard this as a pressing matter (perhaps because of the suggested time frame?) and hence prefer to conveniently ignore it for the time being. It seems to be a classic example of noble intentions of accepted recommendations simply not filtering down to the level where active steps should be taken towards eventual implementation.

\section{CONCLUSION}

The development of Xhosa to the level where it can perform higher functions such as serving as a medium of instruction at institutions of higher learning is possible. For some, like Alexander, this is something that simply has to happen and is, in his thinking, not even negotiable. Taking his cue from the Phillippine scholar Boniface Sibayan, who wrote the seminal The Intellectualization of Filipino (1999), Alexander (2006) is similarly arguing for the 'intellectualisation' of the African languages in South Africa. One aspect of the intellectualisation obviously is the development of the indigenous languages as languages of tuition. Alexander (2003:23) states this unequivocally:

...until and unless we are able to use the indigenous languages of South Africa, among other things, as languages of tuition at tertiary level, our educational system will continue to be skewed in favour of an English-knowing elite.

This development is possible, but whether it would be worth the investment, time and energy in the current educational context in South Africa, is, of course, not easy to answer. It will take a long time to prepare learning material and to train and develop competent staff in all areas of learning and teaching. Besieged African Language departments across the country, being designated to take the lead in this development, are battling to survive given the dramatic drop in student numbers and may not have the energy to devote time to this important but also time-consuming enterprise. All efforts in the medium to long term should probably rather be devoted to the introduction of mother tongue tuition at school level throughout the system. Only once that is in place and working well, can the question of extending mother tongue tuition to higher education be revisited. At the same time it should be said that any organisation, association or individual inspired to become involved in facilitating and participating in this process, should be encouraged to continue with their efforts. Multilingual glossaries that are discipline specific (as suggested by Madiba) are likely to be very useful tools that could be the forerunner of the eventual development and implementation of the indigenous languages as languages of teaching and learning at tertiary level.

It is interesting to note that other African scholars consider South Africa to be well positioned to take this matter forward. Alexander (2003:26) mentions Ayo Bamgbose from Nigeria and Professor A. Abdulaziz from Kenya, who both argue that South Africa, through its Constitutional provisions, the Pan South African Language Board, the National Language 
Service and other associated organisations, are considered 'a shining model' for the rest of the continent. But as we all know, 'it is a model on paper only' (ibid.). Unless the government of South Africa buys into this proposed development, one cannot be blamed for remaining sceptical. What Alexander (2003:14) finally says of the governments in Africa, not mentioning South Africa by name but probably including it, reflects the current state of affairs regarding the language debate in South Africa:

The African elites who inherited the colonial kingdom from the ostensibly departing colonial overlords, for reasons of convenience and in order to maintain their grip on power, have made no more than nominal gestures towards equipping the indigenous languages of the continent with the wherewithal for use in powerful and high-status contexts.

It is important to note Painter's observation (2007:8) concerning the 2007 edition of the HSRC series of country overviews that reflect on the development of post-apartheid South Africa and that cover a wide range of relevant South African phenomena, which points out that language is consistently absent from this series.

Unless there is clear leadership in this regard from government circles that reflects a changed attitude and a commitment that might even call for a decolonisation of the mind (in Ngugi wa Thiong'o's terms), unless private enterprise supports such a move, and unless all institutions of higher learning enthusiastically embrace such a project, the intellectualisation of the indigenous languages, including Xhosa, by developing them as mediums of instruction in higher education in South Africa is likely to remain pie in the sky.

\section{ENDNOTES}

\footnotetext{
${ }^{1}$ This term, although formerly stigmatised in South Africa, is a highly respected and accurate linguistic term in scholarship around the world and should be reinstated in general usage.
}

\section{REFERENCES}

ALEXANDER, N. 2003. The African Renaissance and the use of African languages in tertiary education. PRAESA occasional papers. No. 13. Cape Town: PRAESA/University of Cape Town.

ALEXANDER, N. 2006. The role of African universities in the intellectualisation of African languages. [Online] Available:

http://www.litnet.co.za/taaldebat/intellectualizationalexander.asp [2007, 11 October].

BENSON, C. 2005. The importance of mother tongue-based schooling for educational quality. Commission Study for EFA Global Monitoring Report.

BRINK, C. 2006. No Lesser Place - The taaldebat at Stellenbosch. Sun Press: AFRICAN SUN MEDIA. Stellenbosch.

Language Policy for Higher Education. 2002. Ministry of Education

MADIBA, M. 2006. Mediums of instruction at Higher Education Institutions in South Africa. Unpublished paper read at the Language Policy and Implementation in HEIs conference, UNISA, 5-6 October 
NGUGI WA THOING'O. 1994. Decolonising the Mind. The Politics of Language in African Literature. London \& Portsmouth: James Currey. \& Heinemann.

PAINTER, D. 2007. A new linguistic dispensation: language beyond the nation-state. In JB du Toit \& HC Viljoen (Eds), Proceedings of the Symposium on Multilingualism in South Africa. Stellenbosch, 8 March 2007. iMAG \& TABEMA. 6-9.

PAXTON, MIJ. 2009. 'It's easy to learn when you using your home language but with English you need to start learning language before you get to the concept': bilingual concept development in an English medium university in South Africa. Journal of Multilingual and Multicultural Development, 30(4):345-359.

PECK, A. 2008. A discourse analysis of narratives of identities and integration at the University of the Western Cape. Unpublished MA dissertation, University of the Western Cape.

SIBAYAN, B. 1999. The Intellectualization of Filipino. Manila: The Linguistic Society of the Philippines.

The development of indigenous African languages as mediums of instruction in Higher Education. 2005. Ministerial Committee's report to the Minister of Education.

THE UNIVERSITY OF THE WESTERN CAPE - Language policy 2003. Adapted from original draft discussion document [1998] by Associate Professor Charlyn Dyers, Director, Iilwimi Centre for Multilingualism and Language Professions.

Towards a language plan for the University of Cape Town: 2005-2010. Report of the Task Team.

UNIVERSITEIT VAN STELLENBOSCH - Opsomming: Taalbeleid en plan [Online] Available: http://www.sun.ac.za/taal [2008, 20 May].

UNIVERSITY OF CAPE TOWN - Language Policy 1999 (Revised in 2003) [Online]. Available: http://www.uct.ac.za/downloads/uct.ac.za/about/policies/languagepolicy.doc [2008, 15 May].

VILJOEN, C. 2006. Die Staat en onderrigtaal aan universiteite [Online]. Available: http://www.litnet.co.za/cgibin/giga.cgi?cmd=cause_dir_news_item\&cause_id= 1270\&news_id=3278\&cat_id=216 [2008, 10 May].

WEBB, V. 2002. Language in South Africa. The role of language in national transformation, reconstruction and development. Amsterdam/Philadelphia: John Benjamins.

\section{BIOGRAPHICAL NOTE}

Bertie Neethling is Emeritus Professor in the Xhosa Department at the University of the Western Cape. His main research interests are onomastics (study of names), cross-cultural communication, language acquisition, language policy, oral literature, and translation studies.

E-mail: bneethling@uwc.ac.za 